\title{
Identificación de zonas anegadas y no anegadas mediante técnicas de teledetección
}

\section{Victoria Passucci ${ }^{1}$, Facundo Carmona ${ }^{2}$, Raúl Rivas ${ }^{3}$}

${ }^{1}$ Centro de Investigaciones del Medio Ambiente (CIM), Facultad de Ciencias Exactas, Universidad Nacional de La Plata

${ }^{2,3}$ Instituto de Hidrología de Llanuras (IHLLA), Universidad Nacional del Centro de la Provincia de Buenos Aires E-mail: victoriapassucci@gmail.com

Passucci, V., Carmona, F. \& Rivas, R. (2017). Identificación de zonas anegadas y no anegadas mediante técnicas de teledetección. Revista Estudios Ambientales, 5(2), 51-78. 


\section{RESUMEN}

El seguimiento de inundaciones y sequías tiene un amplio desarrollo a nivel internacional y nacional. En nuestro país, el desarrollo científico es consistente pero con limitaciones de aplicación práctica (95\% de las cuencas hidrológicas de Argentina no disponen de redes de alerta). En este marco se desarrolla el proyecto FONARSEC №19, donde se inserta el presente trabajo, el cual consiste en la utilización de técnicas de teledetección para la identificación de zonas no anegadas que puedan ser tenidas en cuenta para la instalación de las estaciones de monitoreo ambiental. Los métodos analizados fueron: Índice de Agua de Diferencia Normalizada (NDWI gao), Índice de Agua de Diferencia Normalizada Modificado (NDWI $\mathrm{Xu}_{\mathrm{u}}$, análisis de la banda infrarroja media (1,566-1,651 $\mu \mathrm{m})$, Transformación de Tasseled Cap (TTC), clasificación no supervisada (ISODATA) y supervisada (máxima verosimilitud). Como producto final de cada método, aplicado a imágenes del satélite Landsat 8 , se obtuvieron imágenes binarias (zonas anegadas/zonas no anegadas) de la cuenca del Río Salado. La consistencia se analizó con información suplementaria de Google Earth, de vectores de cuerpos de agua permanente y de cursos de agua provistos por el Instituto Geográfico Nacional (IGN), de las imágenes en falso color compuesto de las bandas de reflectividad, y de las características hidrológicas de la cuenca. De este modo, se seleccionaron los dos métodos que mejores resultados brindaron y se realizó un mapa final del estado hídrico de la cuenca y la ubicación potencial de las estaciones de monitoreo ambiental, con el fin de buscar la disminución del riesgo de que dichas estaciones se inunden y generen inconvenientes en los registros de los instrumentos.

Palabras clave: índices de detección de agua, Tasseled Cap, clasificación de imágenes, cuenca del río Salado vertiente sur.

\section{ABSTRACT}

The monitoring of floods and droughts enjoys a wide development at national and international levels. In our country, scientific development is consistent. However, it presents limitations as regards its practical application (95\% of the hydrological basins in Argentina do not have available warning networks). The FONARSEC $\mathrm{N}_{\circ} 19$ project, where the present work is conducted, is developed within this framework, and it involves the use of remote sensing techniques for the identification of nonflooded areas 
that may be taken into consideration in the establishment of the environmental monitoring stations. The analyzed methods were: Normalized Difference Water Index $\left(N D W I_{\text {gao }}\right)$, Modified Normalized Difference Water Index $\left(\mathrm{NDWI}_{\mathrm{Xu}}\right)$, analysis of midinfrared band (1,566-1,651 $\mu \mathrm{m})$, Tasseled Cap Transformation (TCT), unsupervised classification (ISODATA) and supervised classification (maximum likelihood). Binary images (nonflooded areas/flooded areas) of the Río Salado basin were obtained as the final product of each method applied to Landsat 8 satellite images. Consistency was performed with suplementary information from Google Earth, permanent waterbodies and watercourses vectors provided by the Instituto Geográfico Nacional [National Geographic Institute], false-color images composed of reflectance bands, and the basin's hydrological features. Thus, the two methods that provided the best results were selected and a final map was made of the basin hydric status and the potential location for the environmental monitoring stations, aiming to reduce the risk of flooding in such stations, which would cause inconveniences in the records from the instruments.

Keywords: Water detection indexes, Tasseled Cap, Image Classification, Salado River Basin South Slope.

\section{INTRODUCCIÓN}

El presente trabajo de investigación se enmarca dentro del proyecto FONARSEC N 19 "Desarrollo e implementación de sistemas automáticos de alerta de inundaciones y sequías en el área sur de la cuenca del río Salado, provincia de Buenos Aires". El proyecto consiste en la fabricación de estaciones de monitoreo de inundaciones y sequías. Éste es la resultante de una asociación estratégica entre un grupo de investigación (Instituto de Hidrología de Llanuras), una empresa con capacidad de fabricar equipos electrónicos (REDIMEC SRL) y el demandante de la gestión del agua (Autoridad del Agua de la provincia de Buenos Aires) (www.ihreda.com.ar). Los equipos brindarán un conjunto de variantes en la transmisión de la información ambiental garantizando su disponibilidad ante eventos climáticos extremos. Además de la fabricación, el proyecto, contempla los aspectos técnicos y científicos para la ubicación apropiada de las estaciones y la publicación de los resultados ante instituciones públicas y privadas. De este modo se espera responder a las 
necesidades actuales y futuras en cuanto a la disponibilidad de equipos para monitorear cuencas hidrológicas. El objetivo final es tener una red de redes operando en la vertiente sur de la cuenca del río Salado (3,9 millones de hectáreas) que brindará información a 500.000 habitantes y será fundamental en la planificación agroproductiva e industrial del área.

Para llevar adelante la implementación de la red, además de tener en cuenta los criterios hidrológicos y ambientales, se identificaron zonas no anegadas como potenciales sitios de instalación de las estaciones, disminuyendo el riesgo de que estas se inunden generando inconvenientes en los registros de los sensores.

La red de monitoreo contará con estaciones de: monitoreo meteorológicas (EMM), monitoreo freatimétrico (EMF, medición del nivel de agua en acuífero), monitoreo de balance de energía (EMBE), monitoreo limnigráfico (EML, medición del nivel de agua en arroyo) y monitoreo químico (EMQ), estas últimas dos quedan excluidas del análisis que se va a realizar a lo largo del trabajo debido que son instaladas en las cercanías de los cursos de agua.

\section{Marco teórico}

La teledetección espacial permite la observación y caracterización de la superficie terrestre. Para que la observación remota sea posible es necesario que exista una interacción entre los objetos y el sensor, dicha interacción se debe al flujo energético procedente de una fuente de radiación electromagnética, en este caso, el sol. De la energía solar que alcanza la superficie terrestre, una parte es reflejada, devuelta al espacio, y el resto es absorbida o transmitida. La porción de energía devuelta al espacio es definida como la reflectividad, $\rho$, y es la relación entre el flujo de la energía reflejada, $\phi r$, y el flujo de la energía incidente, $\phi i$ :

$$
\rho=\frac{\phi_{r}}{\phi_{i}}
$$

La variación de la reflectividad en función de la longitud de onda define las firmas espectrales. Si se utiliza la ecuación 1 en diferentes anchos de longitudes de onda (lo cual se corresponde con las bandas de las imágenes de satélite) es posible obtener la medida cuantitativa del objeto en una o varias bandas espectrales. Por ejemplo, el agua clara casi no se refleja en la gama del infrarrojo cercano y medio, distinguiéndose muy bien de otras superficies, como suelos y vegetación, principal diferencia utilizada 
para la caracterización de zonas anegadas y no anegadas (Chuvieco, 2002; Sobrino et al., 2000).

Las imágenes seleccionadas para realizar el análisis espacial de la cuenca son las obtenidas por los satélites Landsat 7 y 8 , los cuales tienen a bordo los sensores ETM+ (Enhanced Thematic Mapper Plus) y OLI (Operational Land Imager), respectivamente (Tabla 1). Su mantenimiento y operación están a cargo de la Administración de la Aeronáutica y del Espacio (NASA) y la producción y comercialización de las imágenes del Servicio Geológico de los Estados Unidos (USGS) (Landsat Missions, USGS, 2016).

Tabla 1. Bandas espectrales de sensores OLI y TIRS (Thermal Infrared Sensor) comparadas con las bandas espectrales del sensor ETM+. Tomado de Landsat Missions (USGS, 2016).

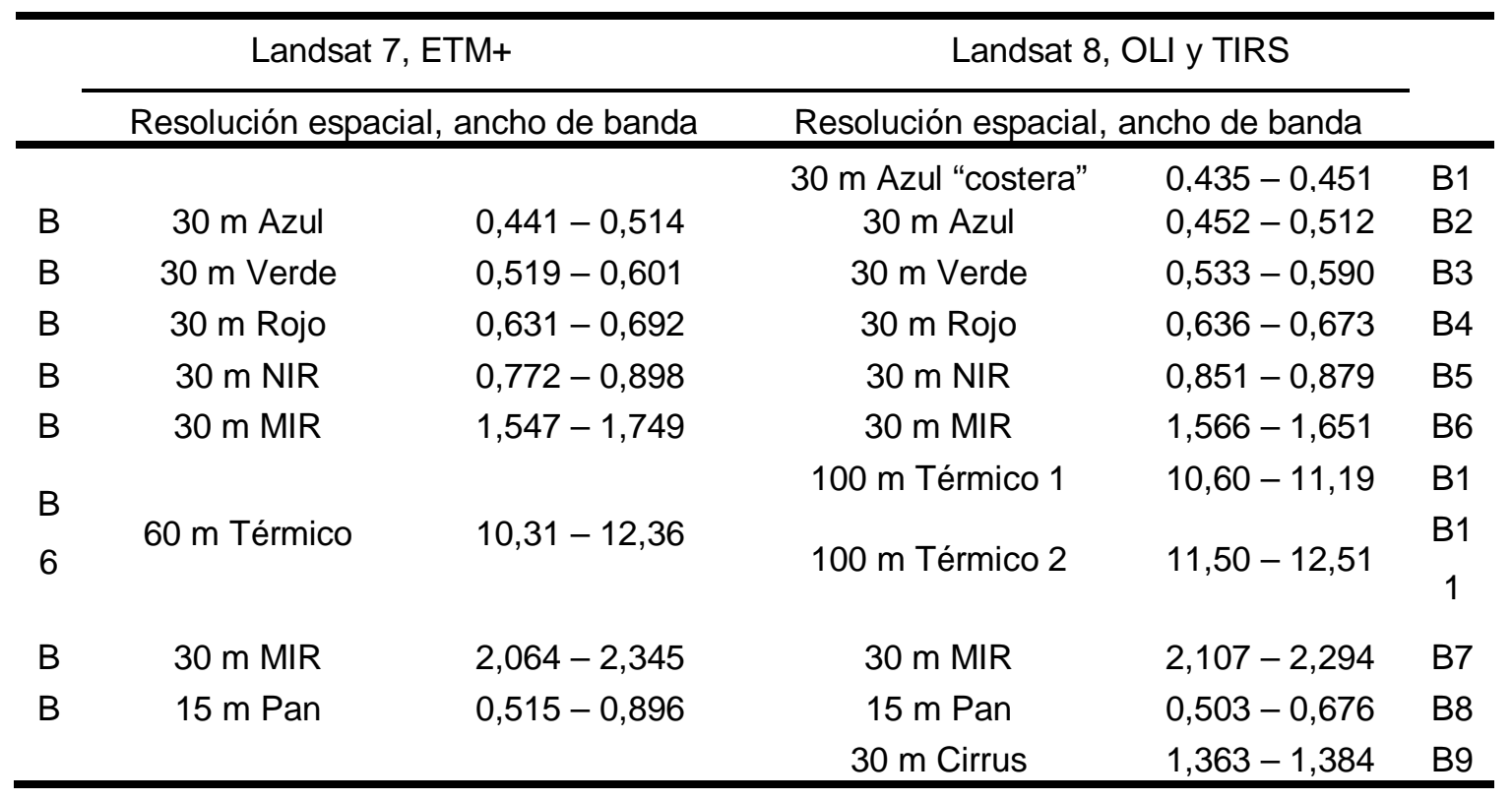

El objetivo del presente trabajo es, mediante el estudio de los registros de precipitaciones diarias (2000-2014), de cinco estaciones del Servicio Meteorológico Nacional (SMN) ubicadas en la cuenca, identificar eventos de máximo ingreso de agua al sistema hidrológico, realizando de este modo la selección de imágenes satelitales, sobre las cuales aplicar diversos métodos de teledetección para poder localizar regiones no anegables (en una situación extrema) como potenciales sitios de instalación de las estaciones de monitoreo ambiental. Los métodos de teledetección a aplicar son: Índice de Agua de Diferencia Normalizada (NDWI gao) (Gao, 1996), Índice 
de Agua de Diferencia Normalizada Modificado $\left(\mathrm{NDWI}_{\mathrm{Xu}}\right)(\mathrm{Xu}, 2006)$, análisis del histograma de la banda infrarroja media (MIR) (Bustamante et al., 2005; Hernández et al. 2009), Transformación de Tasseled Cap (TTC) (Kauth et al., 1976; Crist et al 1986), clasificación de imágenes supervisadas (máxima verosimilitud) y clasificación de imágenes no supervisada (ISODATA) (OCW, UM 2017).

Si bien a lo largo de la investigación se analizaron imágenes Landsat 7 y 8 , se expondrán en el presente trabajo los resultados obtenidos de las imágenes Landsat 8.

\section{MATERIALES Y MÉTODOS}

Área de estudio

La cuenca del río Salado es una región hídrica que se encuentra ubicada en el centro de la provincia de Buenos Aires (Figura 1). La forman una serie de arroyos que corren de sur a noreste por una planicie de escasa pendiente donde diferentes canales ayudan a que las aguas alcancen la bahía de Samborombón. Se la considera de vertiente atlántica por tener obras artificiales que sustituyen la escorrentía natural y le permiten comunicarse con el mar (Ministerio del Interior, 2016).

La región presenta características propias de la llanura donde las pendientes son casi nulas y los micro relieves adquieren importancia, en zonas más bajas se acumula el agua y constituyen bañados, lagunas; es una zona deprimida con deficiente evacuación hídrica donde abundan sistemas de lagunas y hay muy pocos cauces de gran caudal.

La cuenca forma parte de la Región Pampeana, la cual a su vez se puede zonificar en diferentes regiones según su régimen pluviométrico. En este caso, el área de estudio se encuentra ubicada en la zona definida como moderadamente húmeda, con precipitaciones anuales que van desde los 1100 a los 900 mm (Aliaga et al., 2016 a; Aliaga et al., 2016 b). 


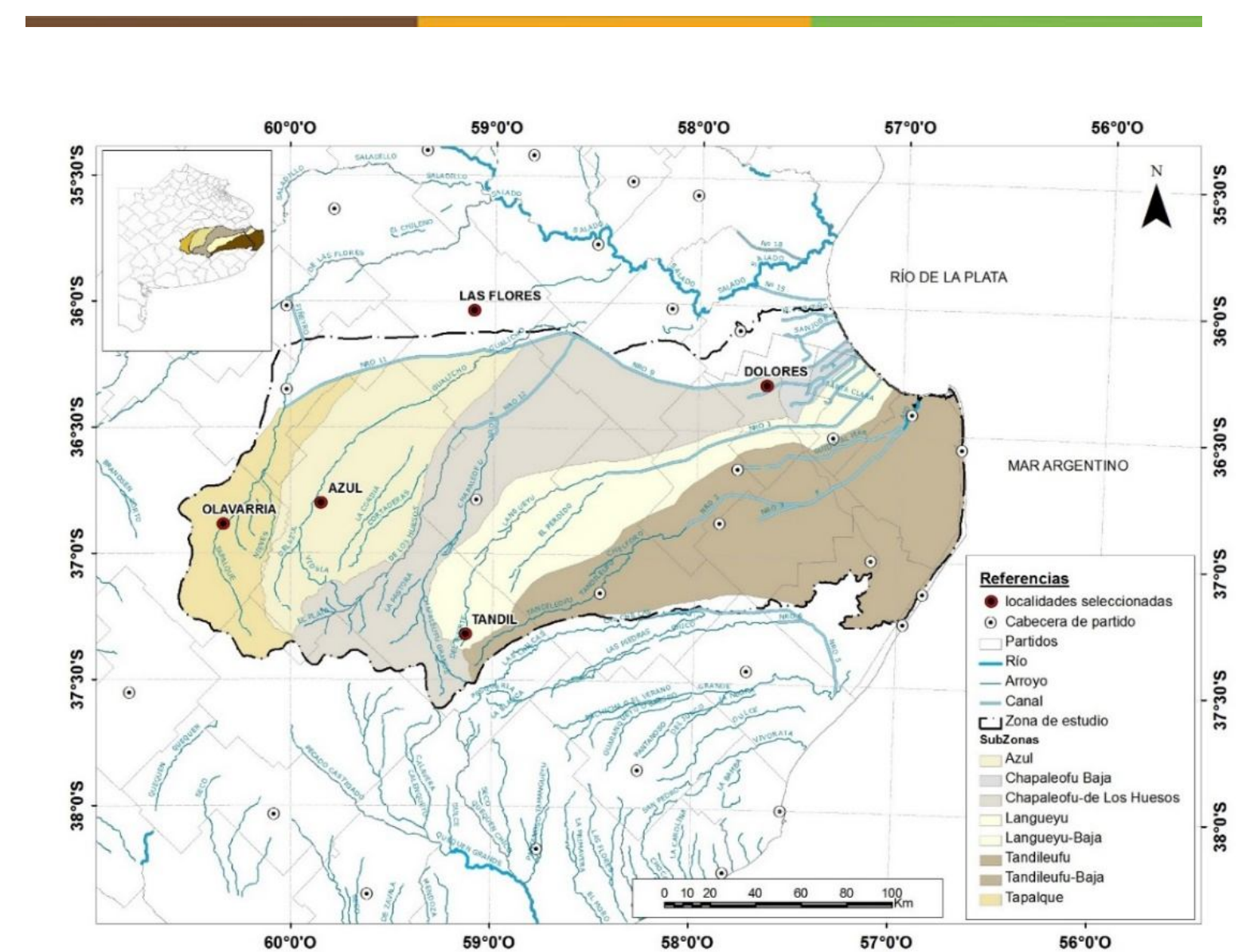

Figura 1. Vertiente sur de la cuenca del río Salado (área de estudio), límite de cuenca, subcuencas y localidades seleccionadas.

\section{Registro de precipitaciones}

Para el periodo 2000-2014 se obtuvieron los datos de precipitaciones diarias (milímetros) de las estaciones de las ciudades de Las Flores, Azul, Olavarría, Tandil y Dolores, pertenecientes a la cuenca del río Salado, para identificar extremos hídricos con condiciones de máxima área anegada. Los datos meteorológicos utilizados, fueron brindados por el SMN. La Tabla 2 muestra la información de cada una de las estaciones y su ubicación geográfica se presenta en la Figura 1. 
Tabla 2. Información de estaciones meteorológicas utilizadas en este trabajo y número de identificación de éstas de acuerdo al SMN.

\begin{tabular}{ccccc}
\hline $\mathrm{N}^{\circ}$ estación & Ciudad & Latitud $\left(^{\circ}\right)$ & Longitud $\left({ }^{\circ}\right)$ & Elevación $(\mathrm{m})$ \\
\hline 87563 & Las Flores & 36,07 & 59,10 & 38 \\
87641 & Azul & 36,83 & 59,88 & 146 \\
87643 & Olavarría & 36,88 & 60,22 & 165 \\
87645 & Tandil & 37,24 & 59,23 & 175 \\
87648 & Dolores & 36,35 & 57,73 & 9 \\
\hline
\end{tabular}

Datos de satélite y técnicas utilizadas

Se seleccionaron cuatro imágenes Landsat correspondientes a las escenas 224/85, 224/86, 225/85 y 225/86 del World-wide Reference System, que cubren la totalidad de la cuenca, descargadas desde el servidor de la ESPA Ordering Interface (USGS, http://glovis.usgs.gov/). A partir de estas imágenes se elaboró un mosaico, sobre el cual, con la ayuda de un vector, se recortó el área de estudio.

Sobre este área de estudio se aplicaron seis métodos de teledetección, utilizando el software ENVI classic 5.3. La consistencia de los métodos se realizó estudiando el resultado de las binarizaciones (píxel negro: zona con agua en superficie, píxel blanco: zona sin agua en superficie), junto con: información suplementaria de Google Earth, vectores de cursos y cuerpos de agua permanente provistos por el IGN y de la imagen de falso color compuesto de las bandas de reflectividad de OLI. Dicha imagen se obtiene asignándole al color rojo la banda 5 , al verde la banda 4 y al azul la banda 3 (RGB: 543), de modo que: la vegetación se aprecia en tonos rojos; los suelos desnudos, secos o áreas rocosas en celeste; en azul oscuro a negro se observa el agua clara; y, colores verdes a verde-azulado corresponden a parcelas aradas o suelos descubiertos con diferente contenido de humedad.

Para la obtención del índice NDWI gao se combinó la banda del infrarrojo cercano (NIR) con la banda del infrarrojo medio (MIR) según Gao (1996) [Ec. 2], resaltando la baja reflectividad que presenta el agua para NIR, el rango de este índice está normalizado entre -1 y 1 , donde los cuerpos de agua tendrán valores positivos cercanos a 1 . 


$$
N D W I_{g a o}=\frac{B 5-B 6}{B 5+B 6}
$$

$B 5$ es la banda correspondiente a NIR y $B 6$ a MIR del sensor OLI

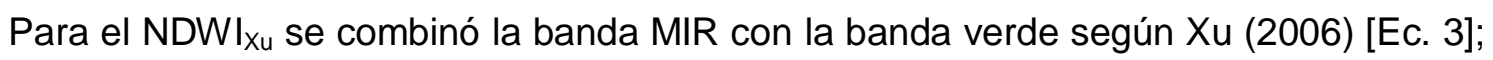
al igual que el índice anterior, sus valores están normalizados entre -1 y 1 , siendo los valores positivos los que caracterizan zonas con agua.

$$
N D W I_{X u}=\frac{B 3-B 6}{B 3+B 6}
$$

3 es la banda verde del sensor OLI

En lo que respecta al análisis del histograma de la banda infrarroja media (MIR), se tiene que la reflectividad de los cuerpos de agua varía con la profundidad, la composición del fondo, la turbidez, entre otras. Sin embargo, en todos los casos, existe un alto porcentaje de absorción en el espectro infrarrojo medio, siendo la reflectividad muy baja, en comparación con los suelos y la vegetación. Por esta razón la banda 6 del sensor OLI, fue seleccionada para estudiar la firma espectral del agua. A su vez es la menos sensible a la carga de sedimentos del agua y por lo tanto la que tiene una mejor capacidad para delinear el límite agua-suelo en aguas turbias (Bustamante et al., 2005).

Tanto a esta imagen, como a las obtenidas por la aplicación de los índices, se les realizó un suavizado para una mejor interpretación de los resultados, donde se aplicó un filtro de convolución de paso bajo; este consiste en producir una imagen de salida en la que el número digital (ND) de un píxel dado sea función de una media ponderada de los ND de los píxeles vecinos, en este caso de una matriz de $5 \times 5$ (Della Vedova, 2013).

Mediante la generación de una máscara, se realizó la binarización de las imágenes para los distintos métodos. Dicha binarización consistió en destacar las zonas anegadas de color negro (valores de ND $=0$ ) y las zonas no anegadas de color blanco (valores de ND = 1).

La TTC, consiste en la obtención de nuevas bandas mediante la combinación lineal de las originales, resaltando el comportamiento espectral de la vegetación y el suelo. Las bandas resultantes se denominan brillo, verdor y humedad y se obtuvieron tras la 
aplicación de los coeficientes expuestos en la Tabla 3, derivados estadísticamente a partir de imágenes y de observaciones empíricas, siendo los ND de sus píxeles adimensionales (Muhammad et al., 2014).La banda que resulta de mayor interés es la de humedad, la cual contrasta la suma de las bandas del visible e infrarrojo cercano, con la suma de las bandas del infrarrojo lejano (Crist et al., 1984).

En primera instancia se analizó la dirección en que la humedad desciende en el plano humedad-brillo, explicado en Crist (1984), realizando un gráfico de dispersión donde en el eje $y$ se representó la banda de humedad mientras que en el eje $x$ la de brillo. Luego, al igual que en los anteriores métodos, se aplicó un filtro de convolución de paso bajo a la banda de humedad y con el análisis del gráfico de dispersión, junto con el análisis del histograma de esta banda, se realizó la binarización del método definiéndose los límites para los cuales los valores de la banda de humedad representan zonas no anegadas.

Tabla 3. Coeficientes de Transformación Tasseled Cap para el sensor OLI.

\begin{tabular}{ccccccc}
\hline \multirow{2}{*}{ Componente } & \multicolumn{7}{c}{ Sensor OLI } \\
\cline { 2 - 7 } & B2 & B3 & B4 & B5 & B6 & B7 \\
\hline Brillo & 0,3561 & 0,3972 & 0,3904 & 0,6966 & 0,2286 & 0,1596 \\
Verdor & $-0,3344$ & $-0,3544$ & $-0,4556$ & 0,6966 & $-0,0242$ & $-0,263$ \\
Humedad & 0,2626 & 0,2141 & 0,09269 & 0,0656 & $-0,7629$ & $-0,5388$ \\
\hline
\end{tabular}

La clasificación digital de imágenes consta en, bajo cierto criterio de similitud, agrupar los píxeles, dando como resultado una nueva imagen que condensa la información digital contenida en las la diversas bandas espectrales que conforman imagen original. Para la clasificación no supervisada no se establece ninguna clase a priori, aunque es necesario determinar el número de clases que se quiere obtener, y se deja que las defina un procedimiento estadístico, debiendo luego un operador identificar a que clases informacionales corresponden. Para el método de ISODATA se seleccionó un intervalo de dos a cuatro clases, con seis iteraciones del método. Para la binarización de la imagen clasificada se seleccionó la clase correspondiente a lagunas y cuerpos de agua permanente como clase 1, información contrastada con Google Earth, y las restantes tres clases (no agua) como clase 2. 
La clasificación supervisada se basa en la disponibilidad de áreas de entrenamiento, conociéndose a priori la clase a la que pertenecen, de modo que mediante un criterio específico de selección se asigna cada píxel a una clase, en este caso al tratarse del método de Máxima Verosimilitud, el criterio es el de la máxima probabilidad de pertenecer el píxel a esa clase.

Para este método, primero se definieron áreas de entrenamiento. Utilizando una composición RGB: 543, se seleccionaron las Regiones de Interés (ROI) a lo largo de toda la cuenca, diferenciando de este modo cuatro tipos de clases: agua, vegetación sana, vegetación enferma o con estrés hídrico y suelo seco. Una vez identificadas las áreas de entrenamiento se aplicó la clasificación y el resultado de este fue binarizado al igual que en el caso de ISODATA.

Ambas clasificaciones se aplicaron a las bandas 2 a 7 del sensor OLI.

Seguidos los pasos anteriores se obtuvo como resultado final seis imágenes que muestran las zonas anegadas y no anegadas, con sus respectivos porcentajes. Por último se seleccionaron los dos métodos que brindaron mejores resultados para realizar un mapa de estado hídrico de la cuenca. La metodología propuesta se sintetiza en el siguiente diagrama de flujo (Figura 2). 


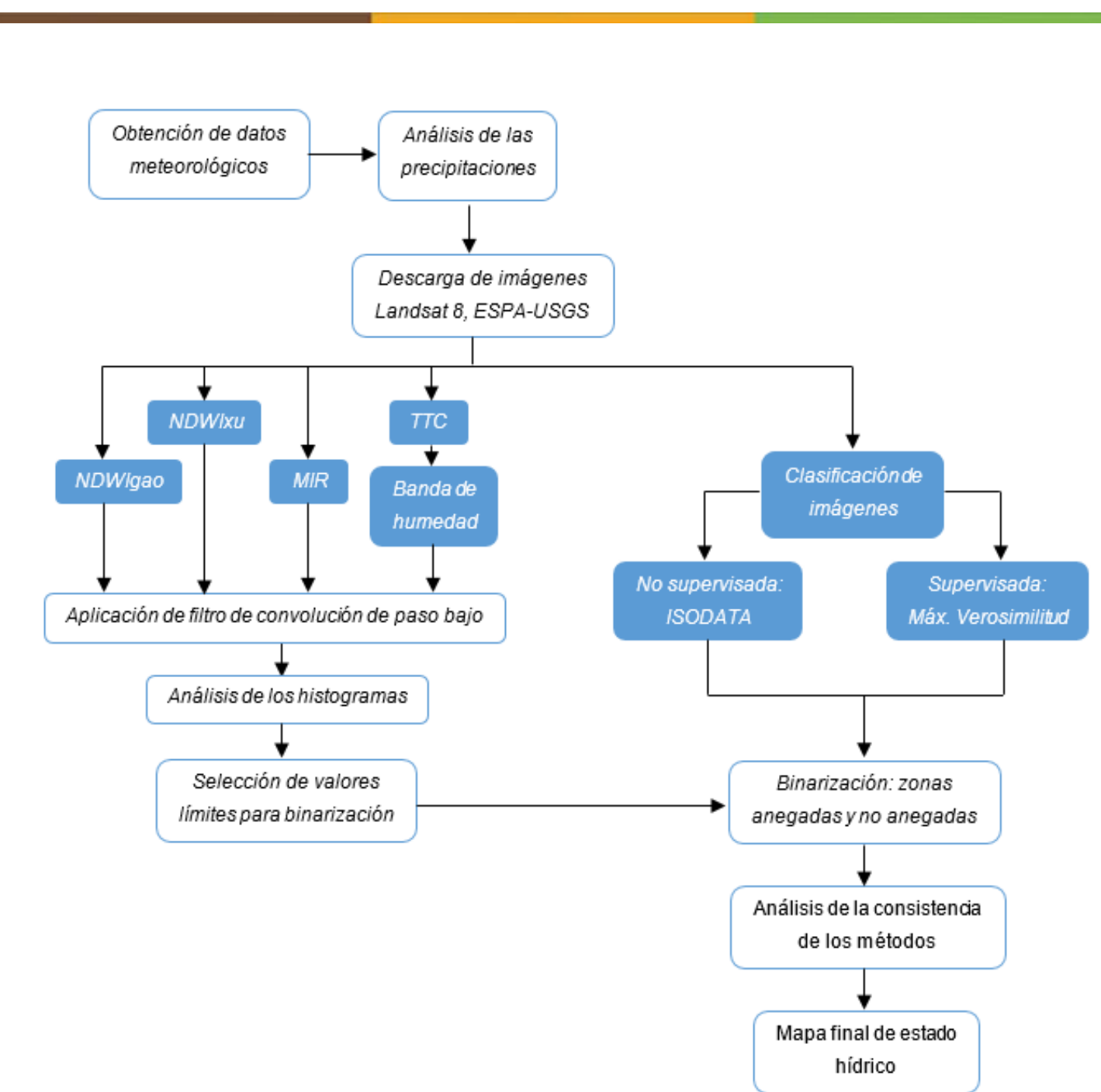

Figura 2. Diagrama de flujo de la metodología aplicada para detectar zonas anegadas y no anegadas.

\section{RESULTADOS Y DISCUSIÓN}

Análisis de precipitaciones y selección de imágenes

Se calculó la precipitación anual promedio teniendo en cuenta las cinco estaciones, destacándose los tres años con mayores registros pluviométricos (2002, 2012 y 2014 , Tabla 4). Con las precipitaciones diarias se realizó, para cada uno de esos años, una distribución mensual para las cinco ciudades, seleccionando de este modo los períodos que tuvieron mayores ingresos de agua al sistema hidrológico. 
Tabla 4. Precipitación acumulada anual en milímetros. En negrita años con precipitaciones elevadas.

\begin{tabular}{ccccccc}
\hline Año & Las Flores & Azul & Olavarría & Tandil & Dolores & Promedio $(\mathrm{mm})$ \\
\hline 2000 & 1053 & 1114 & 950 & 920 & 1060 & 1019 \\
2001 & 1166 & 1350 & 1211 & 1355 & 1196 & 1255 \\
$\mathbf{2 0 0 2}$ & $\mathbf{1 5 3 9}$ & $\mathbf{1 4 0 6}$ & $\mathbf{1 2 1 5}$ & $\mathbf{1 3 1 1}$ & $\mathbf{1 2 7 8}$ & $\mathbf{1 3 5 0}$ \\
2003 & 1053 & 997 & 924 & 940 & 1008 & 984 \\
2004 & 769 & 824 & 730 & 753 & 829 & 781 \\
2005 & 873 & 705 & 761 & 628 & 902 & 774 \\
2006 & 1038 & 920 & 906 & 785 & 1023 & 934 \\
2007 & 962 & 843 & 761 & 621 & 938 & 825 \\
2008 & 740 & 665 & 564 & 524 & 758 & 650 \\
2009 & 830 & 887 & 826 & 629 & 831 & 800 \\
2010 & 983 & 741 & 815 & 909 & 1125 & 915 \\
2011 & 914 & 828 & 804 & 934 & 670 & 830 \\
$\mathbf{2 0 1 2}$ & $\mathbf{1 2 9 5}$ & $\mathbf{1 4 5 2}$ & $\mathbf{1 5 3 4}$ & $\mathbf{1 2 7 1}$ & $\mathbf{1 2 4 3}$ & $\mathbf{1 3 5 9}$ \\
2013 & 743 & 691 & 718 & 763 & 646 & 712 \\
$\mathbf{2 0 1 4}$ & $\mathbf{1 2 2 4}$ & $\mathbf{1 1 4 0}$ & $\mathbf{1 1 8 3}$ & $\mathbf{1 4 0 2}$ & $\mathbf{1 4 0 5}$ & $\mathbf{1 2 7 1}$ \\
\hline
\end{tabular}

Si bien en el trabajo de investigación se analizaron imágenes provenientes de los tres años, en este trabajo se presentan sólo los resultados de los métodos para las imágenes Landsat 8, por lo que nos centraremos en el análisis del 2014.

La distribución mensual de las precipitaciones para el 2014, denota en líneas generales, una distribución homogénea (Figura 3). Si bien se observa un leve aumento de los registros para los meses de otoño y primavera, se decidió trabajar con los meses otoñales debido a que en este período se centran las situaciones críticas. Esto se debe a que los procesos que más condicionan la salida del agua del sistema son los de evapotranspiración (más del $80 \%$ del agua que sale del sistema es a través de este proceso) y debido a la baja radiación para abril-julio en promedio se tiene una evapotranspiración de 1,5 mm por día (Vazquez et al., 2007). 


\section{revista estudios ambientales}

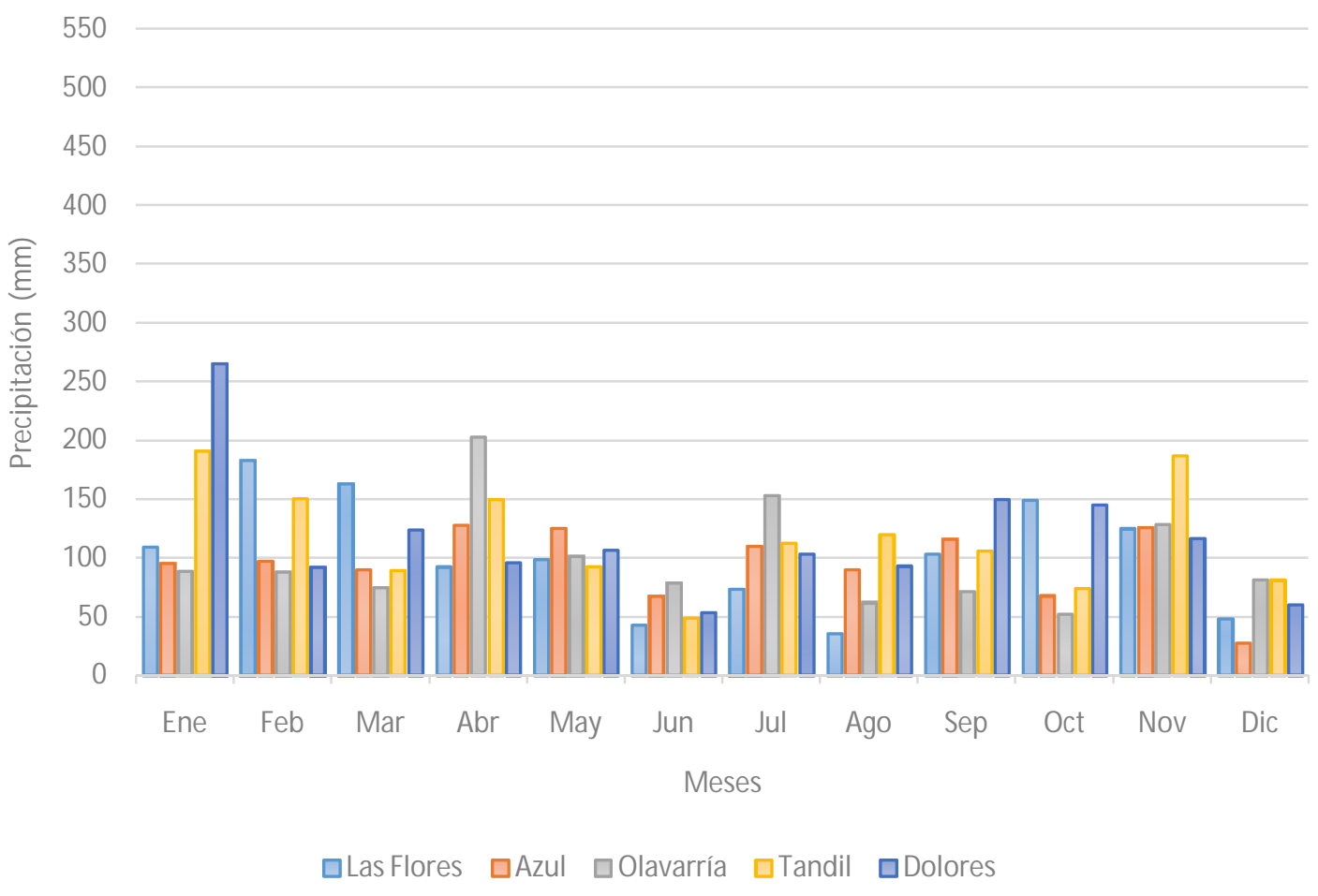

Figura 3. Gráfico de la distribución mensual de la precipitación para las estaciones consideradas, año 2014.

Para el año 2014 se descargaron imágenes pertenecientes a junio. Para la pasada 224 filas 85-86 las imágenes pertenecían al 19/06 y para la pasada 225 fila 85-86 al 10/06 (ESPA, USGS 2016).

\section{Análisis de los métodos aplicados}

Es importante indicar que los símbolos cartográficos fueron excluidos en las Figuras presentadas en el siguiente apartado ya que el análisis se sustenta en los resultados numéricos y en la visualización de las diferentes binarizaciones; sin embargo, la orientación de la cuenca se mantiene en la misma posición de la Figura 1 (norte hacia arriba).

Índice de Agua de Diferencia Normalizada, NDWI gao

Buscando realzar los valores positivos cercanos a 1 que identifiquen sólo regiones con agua, sobre la imagen se aplicaron los vectores del IGN, y se fueron variando los 
límites del histograma, aplicando un ajuste lineal permitiendo la fácil diferenciación visual de las zonas anegadas de las no anegadas.

Se tomó como límite para realizar la binarización del $\mathrm{NDWI}_{\text {gao }}$ el valor de 0,4 , de modo que valores mayores a este son referidos como zonas anegadas (Figura 4). Si bien no se lograron identificar todos los cursos de agua obtenidos a través de los vectores del IGN, si se corría ese límite a valores de $\mathrm{NDWI}_{\text {gao }}$ menores, comenzaban a visualizarse superficies que no presentaban zonas anegadas, como parcelas con vegetación (identificadas en la imagen RGB543), mientras que aún había cuerpos de agua que no quedaban caracterizados como tales. El método demostró tener limitaciones para identificar zonas anegadas.

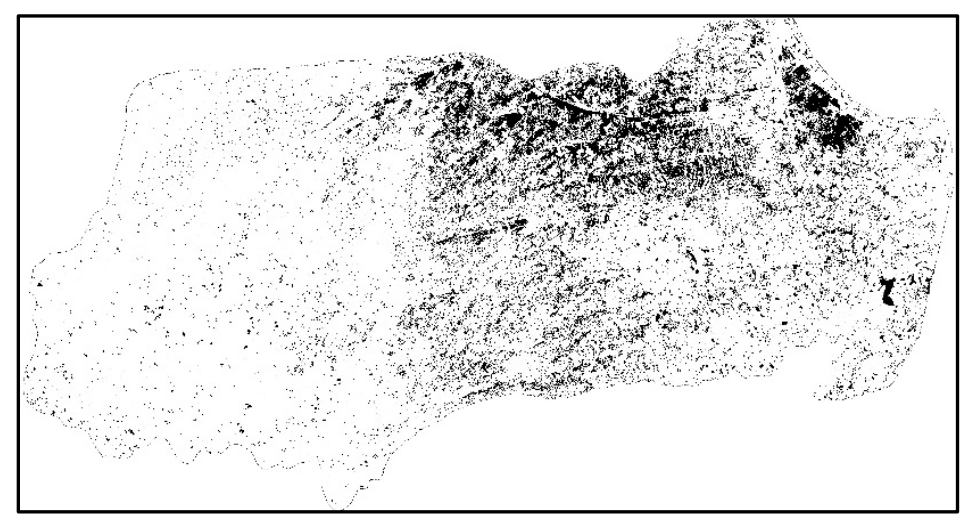

Figura 4. Binarización de $N D W I_{\text {gao }}$, en color negro las zonas anegadas $\left(\mathrm{NDWI}_{\mathrm{gao}} \geq 0,4\right)$ y color blanco las zonas no anegadas (NDWI $\left.\mathrm{gao}_{\mathrm{go}}<0,4\right)$.

Índice de Agua de Diferencia Normalizada Modificado, $N D W I_{X u}$ Los valores de $\mathrm{NDWI}_{\mathrm{Xu}}$ positivos identifican regiones con presencia de agua [Xu, 2006; Campos et al., 2012]. La binarización se realizó previa aplicación del filtro de convolución de paso bajo, al igual que en el método anterior, y se definieron las zonas anegadas para los valores de $\mathrm{NDWI}_{\mathrm{Xu}} \geq 0$ (Figura 5). Como resultado se pudo observar que los cuerpos de agua quedaron caracterizados de forma consistente, mientras que los cursos de agua no se lograron visualizar de forma certera. 


\section{revista estudios ambientales}

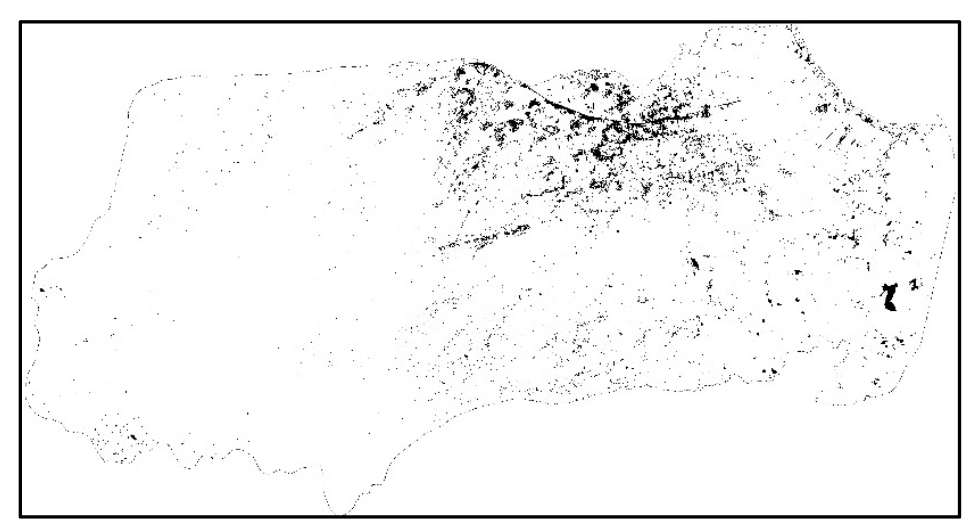

Figura 5. Binarización de $N D W I_{X u}$, en color negro las zonas anegadas $\left(N D W I_{x_{u}} \geq 0\right)$ y color blanco las zonas no anegadas $\left(\mathrm{NDWI}_{\mathrm{Xu}}<0\right)$.

\section{Banda infrarroja media, MIR}

Teniendo en cuenta la firma espectral del agua, se fueron considerando distintos intervalos, de bajas reflectividades, en el histograma de la banda 6 realizando un ajuste lineal, identificando regiones con presencia de agua.

Considerando que las regiones anegadas tienen píxeles mixtos de vegetación y agua, o píxeles con agua encharcada en superficie y materiales en suspensión, se va a tener una reflectividad mayor en contraste a cuerpos de agua profundos y agua clara. Por esta razón, se decidió considerar para la binarización todos los ND $\leq 0,1$ como zona anegada (Figura 6).

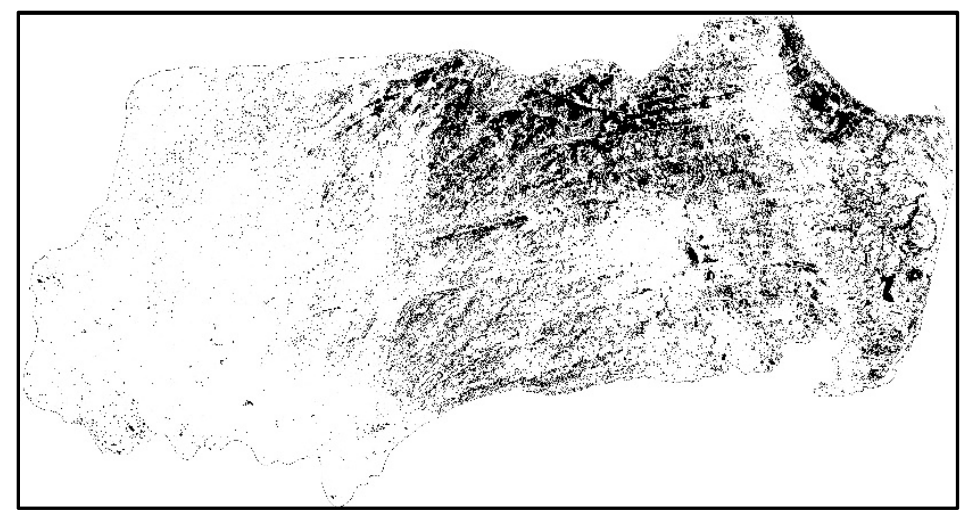

Figura 6. Binarización de MIR, en color negro las zonas anegadas (MIR $\leq 0,1)$ y color blanco las zonas no anegadas (MIR>0,1). 
Con este análisis se lograron visualizar no solo los cuerpos, sino también los cursos de agua y zonas que, en la composición RGB543, eran caracterizadas por un color oscuro, indicando presencia de agua en superficie, dando como resultado mayores áreas anegadas.

\section{Banda de humedad de la Transformación de Tasseled Cap, TTC}

Una vez obtenidas las bandas de brillo, verdor y humedad, se realizó una composición RGB (rojo: brillo, verde: verdor, azul: humedad) en donde se pudieron observar las superficies con presencia de agua en tonalidades azules (Figura 7). Luego, se analizó el gráfico de dispersión (eje $x$ : brillo, eje $y$ : humedad) en distintas zonas de la cuenca que presentaban diversas superficies (ciudades, vegetación, suelo seco, zonas inundadas, cuerpos de agua). Se fueron identificando regiones con agua teniendo en cuenta la dirección en que disminuye la humedad en el plano del suelo (Figura 8) (Crist et al., 1984).

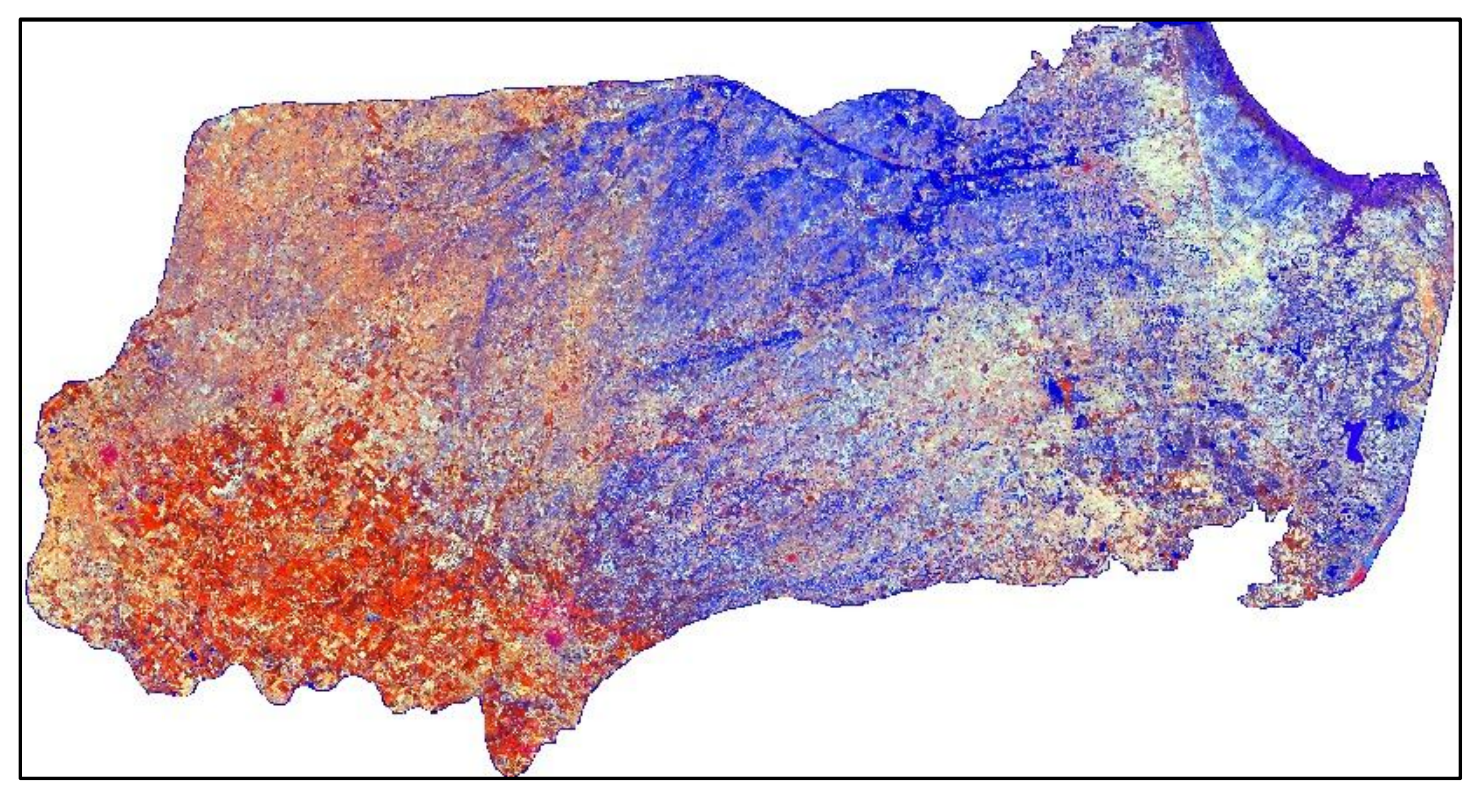

Figura 7. Composición RGB de TTC, rojo: banda de brillo, verde: banda de verdor, azul: banda de humedad. 


\section{revista estudios ambientales}

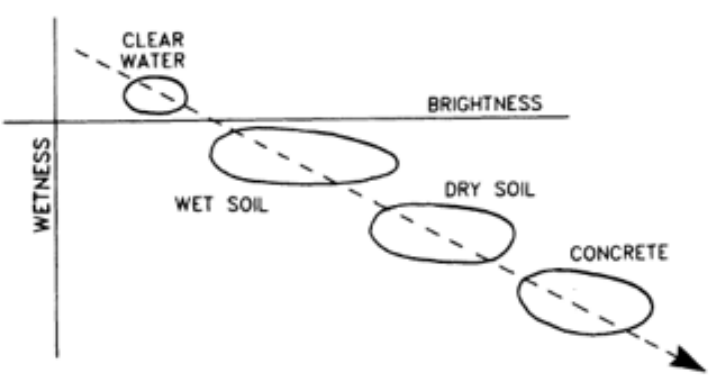

A

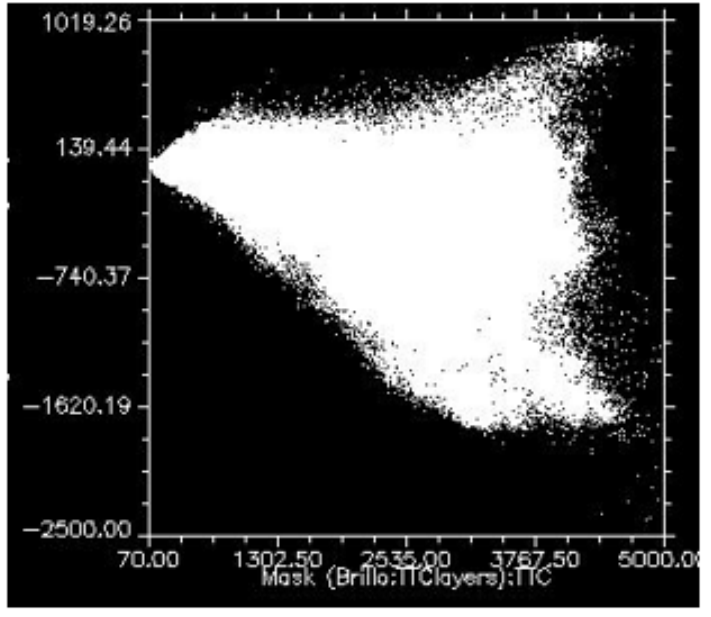

B

Figura 8. A: dirección de la disminución de la humedad en el plano del suelo. [Tomado de Crist et al., 1984]. B: dispersión de los datos del mismo plano del suelo para una región de la cuenca, donde $\mathrm{x}$ : banda de brillo e y: banda de humedad.

De este modo se obtuvieron valores tentativos de la banda de humedad sobre la cual realizar la binarización. Con esos valores se estudió el histograma de la banda de humedad (una vez aplicado el filtro de paso bajo), realizando distintas mascaras binarias, las cuales fueron aplicadas a la composición de falso color compuesto, analizando la relación de las áreas identificadas como zonas anegadas, con las áreas de color azul oscuro a negro. De este modo, se definió que los valores de ND $\geq-100$ representaban zonas anegadas (Figura 9), ya que valores menores a -100 identificaban regiones que no tenían presencia de agua en superficie.

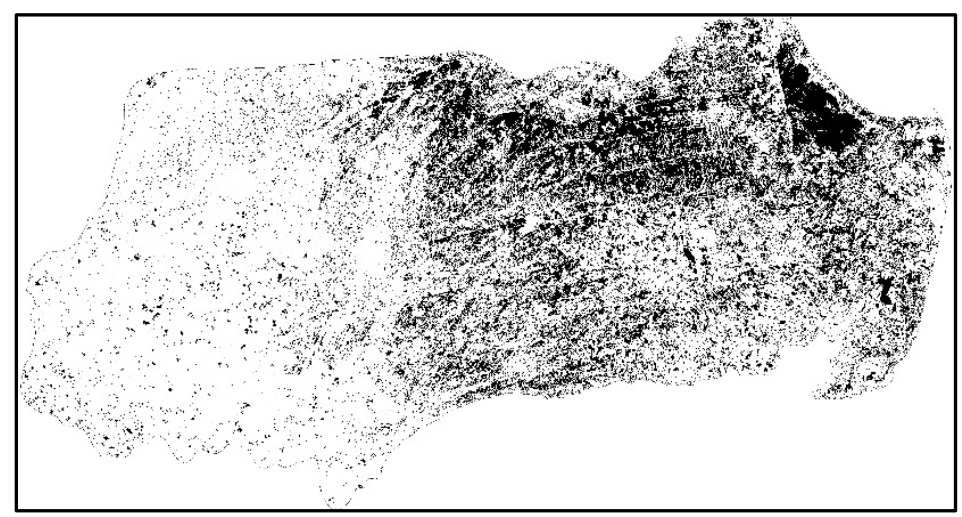

Figura 9. Binarización de la banda de humedad de TTC, en color negro las zonas anegadas $(N D \geq-100)$ y color blanco las zonas no anegadas (ND $<-100)$. 


\section{a}

revista estudios ambientales

No obstante se pudo apreciar que parcelas de un color rojo intenso, que caracterizan parcelas con una vegetación frondosa o elevada humedad, quedaban identificadas como zonas anegadas (Figura 10). Sin embargo, no se pudieron aumentar los valores de ND debido a que dejaban de identificar conocidas superficies con presencia de agua, por ejemplo, en el Google Earth.

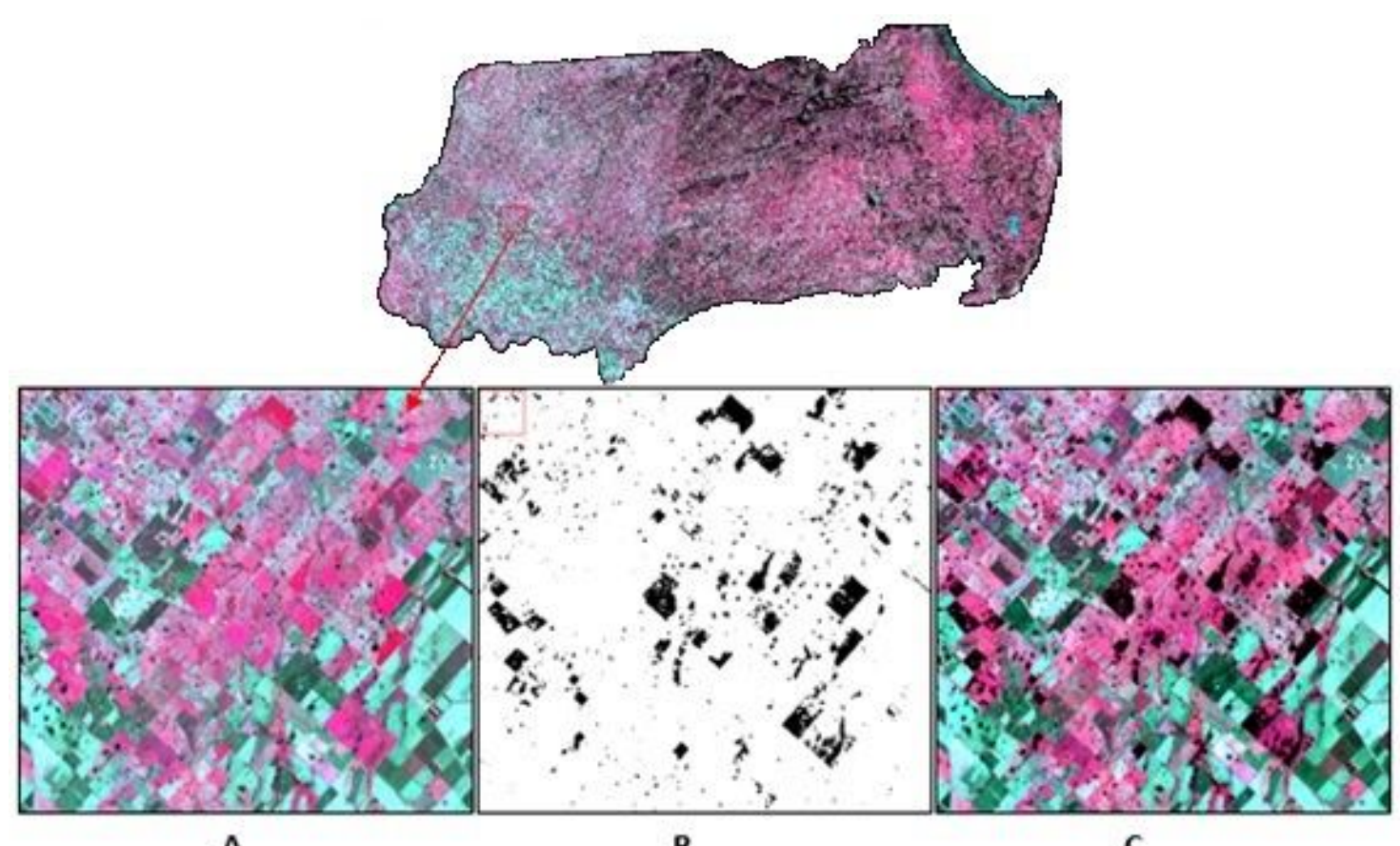

Figura 10. Ubicación de la región seleccionada cercanías a Azul (3652’S; 5947’O). A: composición falso color compuesto. B: binarización de la banda de humedad de TTC para valores de ND $\geq-100$, color negro zonas anegadas, color blanco zonas no anegadas. C: aplicación de la máscara binaria sobre la imagen $\mathbf{A}$.

\section{Clasificación de Imágenes}

En lo que respecta a la clasificación no supervisada (método de ISODATA) aplicado a las bandas 2 a 7 de OLI, una vez identificada la clase perteneciente a agua (color rojo en Figura $11 \mathrm{~A}$ ) las otras tres clases fueron reclasificadas como zonas sin agua (parcelas con vegetación, distintos tipos de suelos, edificaciones, entre otros), obteniéndose la binarización del método (Figura 11 B). 


\section{a \\ revista estudios ambientales \\ publicación digital del CINEA
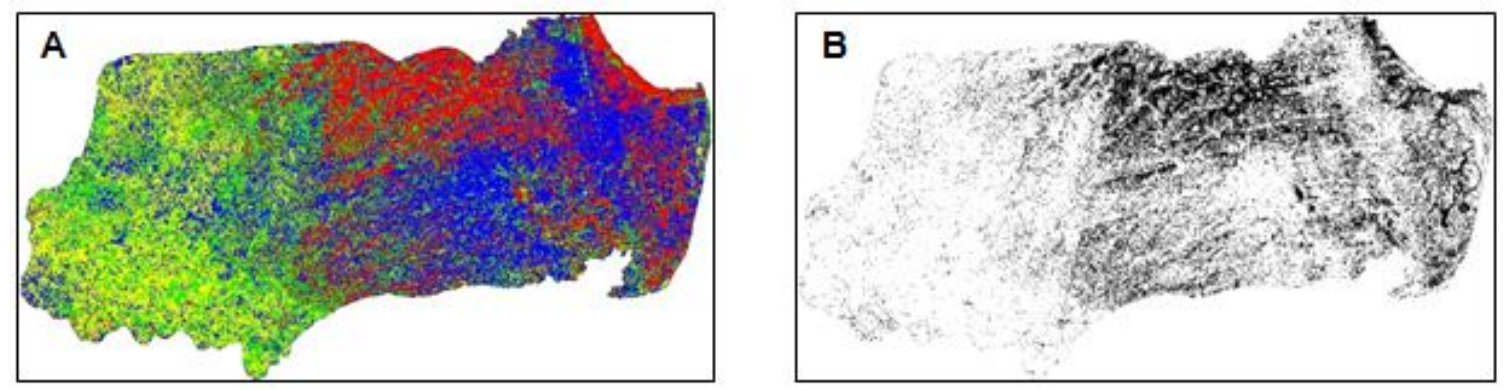

Figura 11. A: Clasificación no supervisada, ISODATA, clase 1 rojo: agua, las otras clases no se identificaron de forma precisa, siendo un conjunto de distintos tipos de suelos. B: binarización de ISODATA, en color negro las zonas anegadas y en blanco las zonas no anegadas.

En cuanto a la clasificación supervisada, luego de definir las áreas de estudio en la composición RGB543, se aplicó el método de Máxima Verosimilitud (bandas 2 a 7 de OLI), obteniendo como resultado final cuatro clases: agua (azul), vegetación (verde), vegetación con menor humedad (amarillo) y suelo seco (rojo) (Figura 12 A). Del mismo modo que para ISODATA, las últimas tres clases se reagruparon como zonas no anegadas, obteniéndose la binarización del método (Figura 12 B).
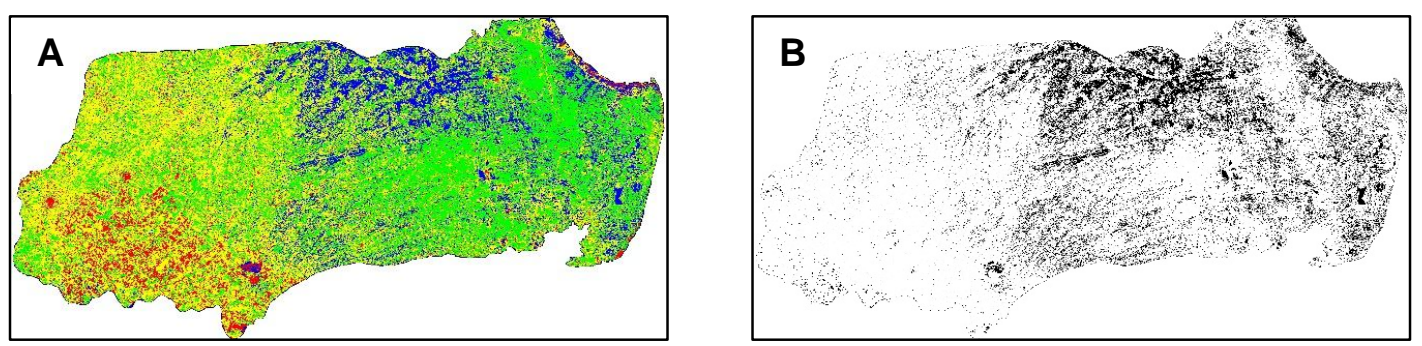

Figura 12. A: Clasificación supervisada, máxima verosimilitud, clase 1 azul: agua, clase 2 verde: vegetación, clase 3 rojo: suelo seco, clase 4 amarillo: vegetación seca. B: binarización del método de Máxima Verosimilitud, en color negro las zonas anegadas y en blanco las zonas no anegadas.

Es de fácil apreciación que el método de ISODATA brindó mayor porcentaje de áreas anegadas que el de Máxima Verosimilitud.

En la Tabla 5, se pueden ver los porcentajes de zonas anegadas y no anegadas obtenidas para cada binarización de los métodos estudiados. 
Tabla 3. Porcentaje de zonas anegadas y no anegadas de las binarizaciones de los métodos.

\begin{tabular}{cccccccc}
\hline \multirow{2}{*}{ Zonas } & \multicolumn{6}{c}{ Métodos } \\
\cline { 2 - 7 } & NDWI gao & NDWI $_{\text {Xu }}$ & MIR & TTC & ISODATA & Máx. Verosimilitud \\
\hline$\%$ Anegada & 13 & 3 & 17 & 27 & 22 & 15 \\
$\%$ No anegada & 87 & 97 & 83 & 73 & 78 & 85 \\
\hline
\end{tabular}

\section{Obtención del mapa de estado hídrico}

Las binarizaciones del $\mathrm{NDWI}_{\text {gao }}$ y $\mathrm{NDWI}_{\mathrm{Xu}}$ se despreciaron debido a sus limitaciones para identificar las zonas anegadas y brindar resultados por debajo de los otros métodos.

En lo que respecta a los métodos de clasificación de imágenes, al realizar la suma de ambas binarizaciones, se encontró que las áreas anegadas identificadas por ISODATA expandían las obtenidas en la clasificación supervisada. Considerando que se busca resguardar a las estaciones de monitoreo de posibles inundaciones que discontinúen sus mediciones, la clasificación supervisada fue despreciada.

Para realizar una comparación de los dos métodos que mayores porcentajes de zonas anegadas presentaron (TTC e ISODATA), se seleccionaron cuatro regiones de la cuenca sobre las cuales se aplicaron las binarizaciones a la imagen de falso color compuesto (Figura 13).

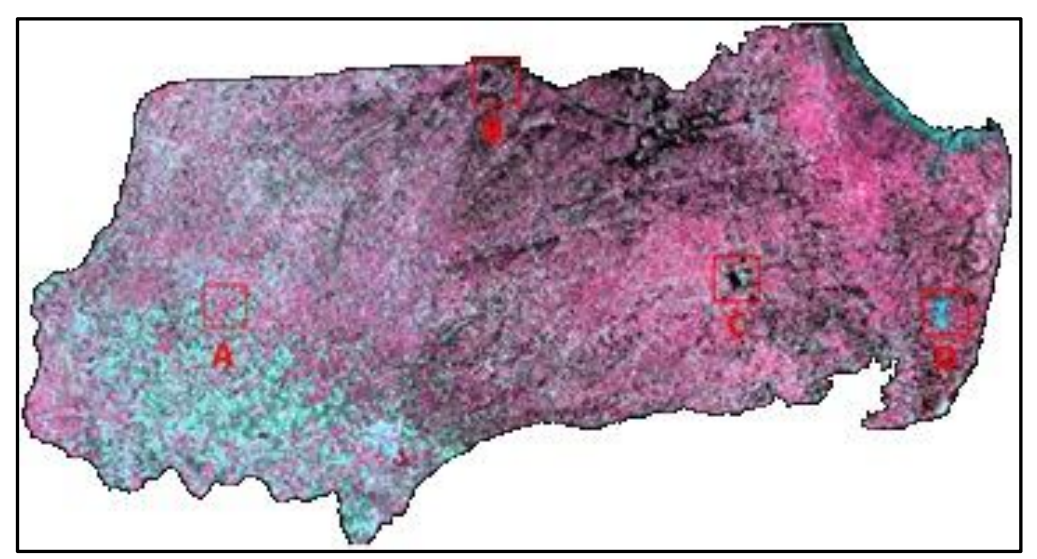

Figura 13. Composición falso color compuesto de la cuenca, indicando cuatro regiones: inmediaciones de la ciudad de Azul (3652'S; 5947’O). B: intersección de canales en el límite

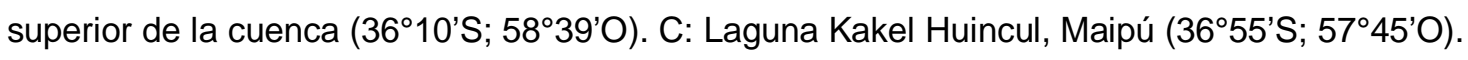
D: Laguna Salada, Madariaga ( $36^{\circ} 55^{\prime} S$; $56^{\circ} 57^{\prime} O$ ). 
En la Figura 14 se aprecian zonas anegadas ubicadas en las mismas regiones con ambos métodos donde, en algunos casos, se observa que el área obtenida por el método de TTC es mayor. Sin embargo, las parcelas de un color rojo intenso bajo la TTC fueron definidas como zonas anegadas, mientras que con ISODATA se definieron como no anegadas. El color rojo intenso de la imagen de falso color compuesto, pudo deberse a que la vegetación presentaba una elevada humedad o que existía un encharcamiento por debajo de esta. Debido a que no se pudo saber con certeza cuál era la característica de estas superficies, se decidió seleccionar el método de ISODATA que las definía como zonas no anegadas, despreciando los resultados de la TTC ya que probablemente sobreestima la binarización de la banda de humedad. 


\section{7}

revista estudios ambientales

Volumen 5 N², año 2017

publicación digital del CINEA

ISSN: 2347-0941

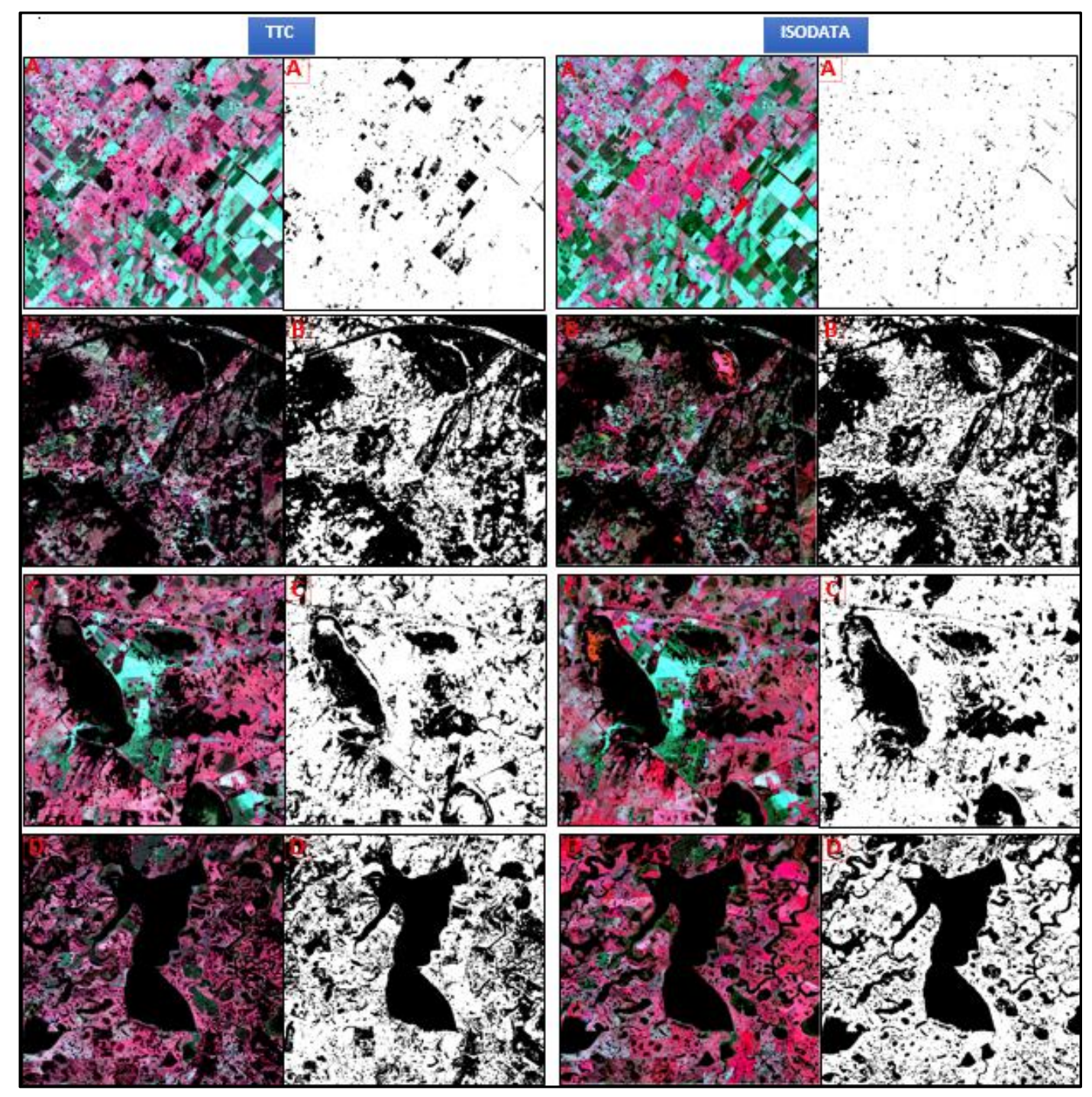

Figura 14. Imágenes binarias y aplicación de las máscaras a la composición falso color

compuesto de las cuatro regiones de la cuenca. A: inmediaciones de la ciudad de Azul

(3652'S; 5947'O). B: intersección de canales en el límite superior de la cuenca (36¹0'S; $\left.58^{\circ} 39^{\prime} \mathrm{O}\right)$. C: Laguna Kakel Huincul, Maipú ( $36^{\circ} 55^{\prime}$ ' $\left.; 5^{\circ} 45^{\prime} \mathrm{O}\right)$. D: Laguna Salada, Madariaga (365 $55^{\prime}$; $\left.56^{\circ} 57^{\prime} O\right)$.

El tercer método que arrojó mayores porcentajes de zonas anegadas (Tabla 5) fue el análisis de la banda infrarroja media, en la cual al existir una diferencia significativa entre los valores de reflectividad para zonas con vegetación, suelo, edificaciones y agua, el error de identificar una región con agua "siendo que no es agua" es menor que en el resto de los métodos. 
Una vez analizado cada método, buscando integrar la información brindada por los dos métodos más confiables (ISODATA y MIR), se realizó el mapa de estado hídrico de la cuenca sumando ambas imágenes.

En la Figura 15 se aprecia el mapa final de estado hídrico de la cuenca para el 2014 junto con la ubicación de las distintas estaciones de monitoreo ambiental, donde en color blanco se identifican las zonas no anegadas y en color verde las zonas anegadas.

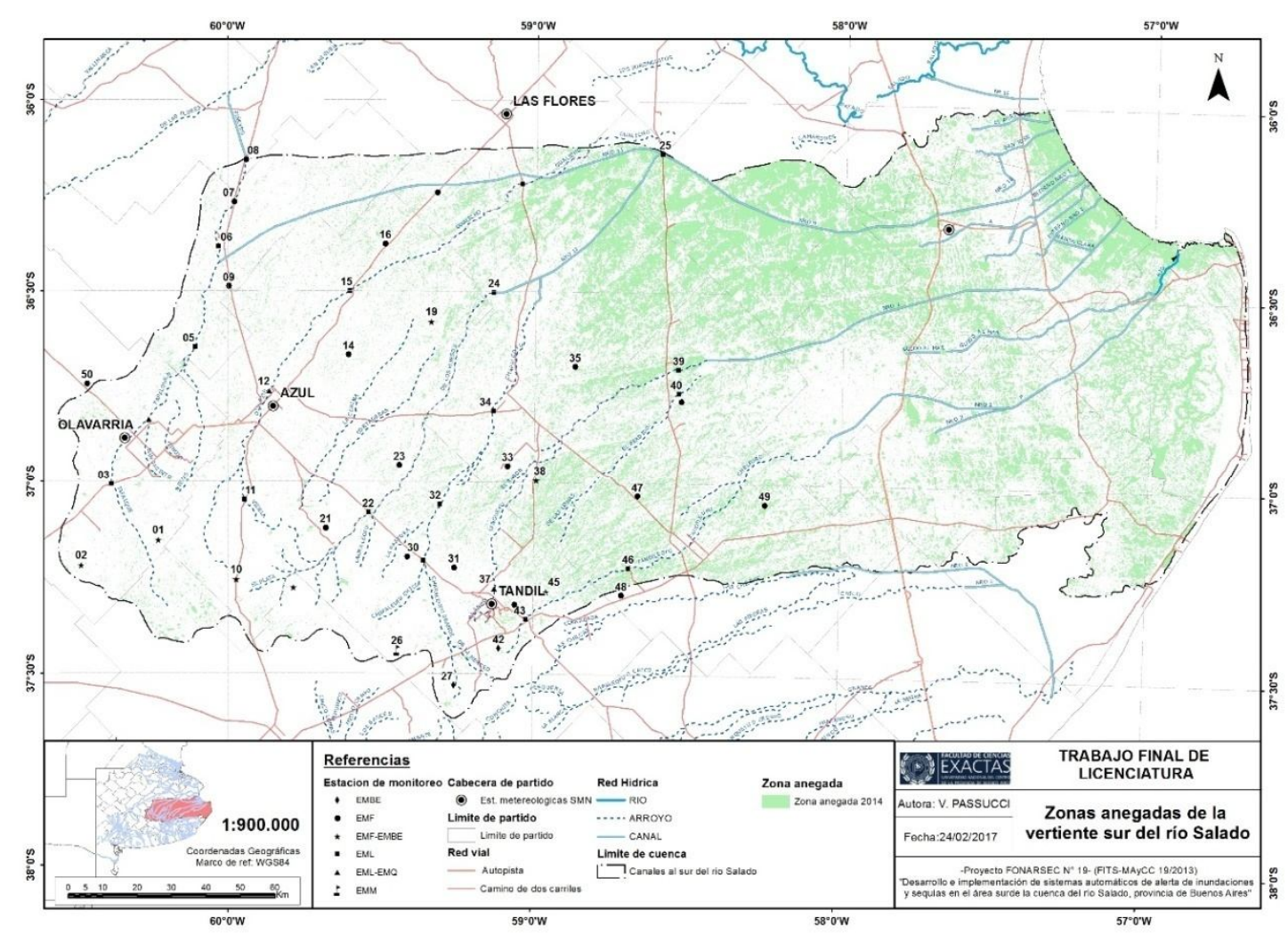

Figura 15. Mapa del estado hídrico para el año 2014, cuenca del Río Salado. Ubicación de las estaciones de monitoreo ambiental. Métodos utilizados para caracterizar zonas anegadas: clasificación no supervisada (ISODATA) y análisis de la banda MIR .

Para la ubicación final de las estaciones se tuvieron en cuenta la posible instalación en las áreas blancas del mapa y a su vez, en lugares que cumplieran los criterios hidrológicos y ambientales necesarios requeridos en un sistema de monitoreo. En el caso que alguna de las estaciones corra riesgo de anegamiento por encontrarse cerca 
de arroyos, como lo pueden ser las estaciones de monitoreo freatimétricos 7 y 8 , se tomarán los recaudos constructivos al momento de la ejecución de la obra civil.

\section{CONCLUSIONES}

Se concluyó que los índices NDWI y MNDWI no son los adecuados para los objetivos del trabajo realizado, debido a las dificultades de establecer límites numéricos de referencia a partir de los histogramas de frecuencia.

Los métodos que arrojaron mejores resultados, por considerar un área elevada de zonas anegadas y al mismo tiempo no sobreestimar estos resultados, fueron la clasificación no supervisada (ISODATA) y el análisis de la banda infrarroja media (MIR).

Si bien se concluyó que la binarización de la banda de humedad de la Transformación de Tasseled Cap sobreestimaba las regiones anegadas (incorporando áreas vegetadas como anegadas), se pudo concluir que es una técnica consistente al momento de analizar eventos extremos en áreas puntuales (áreas próximas a ciudades, caminos, parcelas en campos, entre otras) y de combinarse con otros métodos.

Se lograron definir los sitios potenciales de instalación para la red de monitoreo ambiental y se dejó un registro de distintas técnicas de teledetección que no solo brindan información en lo que respecta a la detección de agua en superficie, sino que también pueden ser utilizadas para la identificación de distintos tipos de suelos. Esta combinación de información (satelital y de terreno por las estaciones de monitoreo) permite la caracterización y seguimiento de fenómenos naturales de una forma más completa.

\section{AGRADECIMIENTOS}

Este trabajo es el resultado final de la investigación llevada a delante como Trabajo Final de la Lic. en Tecnología Ambiental. Se realizó en parte bajo el financiamiento de la Beca de Estímulo de las Vocaciones Científicas otorgada por el Consejo Interuniversitario Nacional (EVC-CIN), en el 2015, y en marco del proyecto FONARSEC N¹9, trabajando en conjunto con el grupo de Teledetección del IHLLA, sede Tandil. 
Al Servicio Meteorológico Nacional por los datos de las precipitaciones diarias de sus estaciones en las ciudades Las Flores, Azul, Olavarría, Tandil y Dolores.

\section{BIBLIOGRAFÍA}

Aliaga, V. S., Ferrelli, F., Alberdi-Algañaraz, E. D., Bohn, V. Y., Piccolo, M. C. (2016 a). Distribución y variabilidad de la precipitación en la Región Pampeana, Argentina. Cuadernos de investigación Geográfica, 42 (1), 261-280. Disponible en: https://dialnet.unirioja.es/servlet/articulo?codigo=5607402. Fecha de consulta: Julio 2017

Aliaga, V. S., Ferrelli, F., Bohn, V. Y., Piccolo, M. C. (2016b). Utilización de imágenes satelitales para comprender la dinámica lagunar de la Región Pampeana. Revista de Teledetección, 46, 1-14. Disponible en: http://ri.conicet.gov.ar/handle/11336/21356. Fecha de consulta: Julio 2017

Bustamante, J., Díaz-Delgado, R., Aragonés, D. (2005). Determinación de las características de masas de aguas someras en las marismas de Doñana mediante teledetección. Revista de Teledetección, 24, 107-111. Disponible en: http://www.aet.org.es/revistas/revista24/AET24-19.pdf. Fecha de consulta: Julio 2017

Campos, J. C., Sillero, N., Brito, J. C. (2012). Normalized difference water indexes have dissimilar performances in detecting seasonal and permanent water in the Sahara-Sahel transition zone. Journal of Hydrology, 464-465, 438-446. Disponible en: http://www.sciencedirect.com/science/article/pii/S0022169412006592. Fecha de consulta: Julio 2017

Chuvieco, E. (2002). Teledetección ambiental, la observación de la Tierra desde el Espacio. Ariel S.A. (Ed).

Crist, E. P, Cicone, R. D. (1984). A Physically-Based Transformation of Thematic Mapper Data-The TM Tasseled Cap. IEEE Transactions on Geosciencie and Remote Sensing, 22 (3), 256-263. Disponible en: http://www.geo.umass.edu/courses/geo594q/Crist1984IEEETasseledCap.pdf. Fecha de consulta: Julio 2017 
Crist, E.P., Kauth, R. J. (1986). The Tasseled Cap De-Mystified. Photogrammetric Engineering and Remote Sensing, 52 (1), 81-86. Disponible en: https://www.asprs.org/wp-content/uploads/pers/1986journal/jan/1986 jan 8186.pdf. Fecha de consulta: Julio 2017

Della Vedova, M. (2013). Filtros y técnicas de clasificación en imágenes de teledetección. Trabajo Especial de Licenciatura en Ciencias de la Computación. Facultad de Matemática, Astronomía y Física Universidad Nacional de Córdoba. Córdoba, 138 páginas.

ESPA, USGS. 2016. United States Geological Survey USGS, sección: Earth Resources Observation and Science (EROS) Center Science Processing Architecture (ESPA) On Demand Interface. Disponible en: https://espa.cr.usgs.gov/login?next=http\%3A\%2F\%2Fespa.cr.usgs.gov\%2F.

Fecha de consulta: 10/05/2016.

Gao, B. (1996). NDWI-a normalized difference water index for remote sensing of vegetation liquid water from space. Remote Sensing of Environmental, 58, $256-266$.

Hernández, H. J., Montaner, D. (2009). Patrones de Respuesta Espectral. En: Tecnologías Geoespaciales: Experiencias Aplicadas al Estudio y Gestión del Territorio. Carlos Mena (Ed.) ISBN: 978-956-7717-14-7. Disponible en: http://www.gep.uchile.cl/Publicaciones_gep.html. Fecha de consulta: enero 2017.

Kauth, R. J., Thomas, G. S. (1976). The Tasselled Cap-A Graphic Description of the Spectral-Temporal Development of Agricultural Crops as Seen by LANDSAT. LARS Symposia. Paper $159 . \quad$ Disponible en: http://docs.lib.purdue.edu/lars symp/159/. Fecha de consulta: Julio 2017

Landsat Missions, USGS 2016. United States Geological Survey USGS, sección: About Landsat. Disponible en: https://landsat.usgs.gov/. Fecha de consulta: diciembre 2016.

Ministerio del Interior, 2016. Disponible en: http://www.mininterior.gov.ar/obraspublicas/pdf/49.pdf. Fecha de consulta: abril 2016. 
Muhammad Hasan, A. B., Zhang, L., Shuai, T., Tong, Q. (2014). Derivation of a tasseled cap transformation based on Landsat 8 at-satellite reflectance. Remote Sensing Letter, 5 (5), 423-431.

OCW, UM 2017. Open Course Ware, Universidad de Murcia. Sección: lista de cursos, Ciencias, material de clases. Disponible en: http://ocw.um.es/ciencias/herramientas-de-teledeteccion-aplicadas-ala/material-de-clase . Fecha de consulta: enero 2017.

Sobrino, J. A., Raissouni, N., Kerr, Y., Olioso, A., López-García, M. J., Belaid, A., El Kharraz, M. H., Cuenca, J., Dempere, L. (2000). Teledetección. J. A. Sobrino (Ed), Servicio de Publicaciones, Universidad de Valencia, Valencia (España).

Vazquez, P., Masuelli, S., Platzeck, G., Boolsen, O. (2007). Recurrencia de anegamiento en la depresión del río Salado: subcuenca B4. TELEDETECCIÓN - Hacia un mejor entendimiento de la dinámica global y regional. Martin (Ed), 171-178. Disponible en: http://dns2.aet.org.es/congresos/xii/arg22.pdf. Fecha de consulta: Julio 2017

$\mathrm{Xu}, \mathrm{H}$. (2006). Modification of normalised difference water index (NDWI) to enhance open water features in remotely sensed imagery. International Journal of Remote Sensing, 27 (14), 3025-3033. 